\title{
LA LITERATURA INFANTIL COMO FORMADORA DE IDENTIDADES NACIONALES, EN ECUADOR Y EN SUDAMÉRICA
}

Bernarda Franco, M.A.

\section{RESUMEN}

El presente artículo explora la trayectoria de la literatura infantil iberoamericana, y en especial, de la ecuatoriana, la cual ha atravesado por cambios durante la última década; su difusión ha mejorado, contribuyendo a que los jóvenes y niños ecuatorianos tengan acceso a estas obras que, en la mayoría de los casos, apelan a sus raíces, tradiciones y costumbres. Es esencial analizar las nociones como nación e identidad nacional, específicamente, en el ámbito ecuatoriano, así como las obras infantiles más relevantes y su papel en la formación de identidades nacionales; aun cuando la literatura infantil en el país no ocupa el lugar que le corresponde.

\section{PALABRAS CLAVES}

Obras infantiles, identidad, nación, juventud, infancia

\begin{abstract}
This article explores the path of the children literature in Latin America, and more particularly in Ecuador, which has gone through changes in the last decade; its dissemination has improved, benefiting the young people and children from Ecuador to have access to these works, which in many cases appeal to their roots, traditions and customs. It is essential to analyze notions like nation, and national identity, specifically in the Ecuadorian milieu, as well as the most relevant children's works and their role in the building of national identity; even when children literature is not in the place it deserves.
\end{abstract}

\section{KEYWORDS}

Children's Works, Identity, Nation, Youth, Childhood

Depositado en agosto 15 de 2014, aprobado en octubre 31 de 2014.

1 Licencia en educación de la Universidad Católica de Santiago de Guayaquil, Ecuador. Magister en Artes Liberales de la Universidad de Miami, Florida. Doctorante en Sociología de la Universidad Nacional Mayor de San Marcos, Lima - Peru. bfranco@uees.edu.ec 


\section{INTRODUCCIÓN}

La identidad nacional en el Ecuador es un asunto que no termina debido a problemas internos como el regionalismo y a un marcado desinterés por lo nacional. Establecida así la situación, queda por averiguar qué le espera a las generaciones más jóvenes del país, cómo lograrán identificarse con lo suyo. Es así, cómo surge como una alternativa - entre otras - la literatura infantil, formadora del pensamiento, que con su gran poder integrador ha resurgido en el Ecuador durante los últimos diez años procurando, en la mayoría de los casos, inculcar valores culturales a través de la difusión de información sobre este país multiétnico y pluricultural.

Nuestro país necesita crear el hábito de la lectura y la enseñanza, pues como recordaba Jorge Luis Borges en una de sus numerosas entrevistas que relata Martín Arias y Martín Hades (2000), éste expresó en su momento "A mí me gusta mucho enseñar, sobre todo porque mientras enseño, estoy aprendiendo". Más aún, agregó al referirse a la cátedra "como una de las felicidades que me quedan" y aquello nos recuerda a una foto extraordinaria en la que Ernesto Guevara está en Bolivia, subido a un árbol, leyendo en medio de la desolación y la experiencia terrible de la guerrilla perseguida. Se sube a un árbol para aislarse un poco y está allí, leyendo.

La lectura para Ernesto Guevara, según nos recuerda Piglia (2005) en el libro "El último lector", aunque no coincidamos con su pensamiento político, es importante describirla con sus propias palabras, impuestas en el Congo, dice así "El hecho de que me escape para leer, huyendo así de los problemas cotidianos, tendía a alejarme del contacto con los hombres, sin contar que hay ciertos aspectos de mi carácter que no hacen fácil el intimar."

También es necesario recordar la cita que se hace en cuanto a Don Quijote y Sancho, en la decisión milagrosa de Cervantes que, - luego de la primera salida - hace entrar al que no lee, su escudero, quien expresa con cierta hilaridad "Pues a fe mía, que no sé leer", respondió Sancho. Ese encuentro, ese diálogo nos enseña la situación del Ecuador, pues hay una confronta- ción entre lectura y oralidad, que debe ser superada entre los hombres y mujeres ecuatorianos.

Por todo aquello, la reforma de instrucción pública se hace necesaria en mi país, y aún más, en los comienzos de la niñez, pues resulta alarmante lo que ha señalado el Ministro de Educación, Augusto Espinoza, al afirmar "La formación docente en el país no es satisfactoria", y alega que la formación inicial es insuficiente en lo disciplinario y metodológico, existiendo carencia de investigación. En el Diario El Universo, primera sección, de fecha 28 de julio del 2013, bajo el título "Docentes extranjeros para nueva universidad", se hace referencia a la búsqueda de profesores extranjeros - que en la práctica se hace necesaria - tan cierto es aquello que Luis Robalino Dávila en su obra "Orígenes del Ecuador de hoy", relata que no era educación el régimen carcelario de las escuelas y colegios, implantado por "excelentes y buenas" personas pero sin preparación adecuada para la ardua tarea, más aún, para la educación infantil que necesita de una preparación más adecuada para su formación.

André Maurois trata sobre el asunto que estamos comentando en su recordada obra "Un arte de vivir" (1939) al decir "¿es un trabajo la lectura?" y con Valerie Larbaud expresa "la lectura es un vicio impune" y recuerda a Descartes, quien decía que aquélla "es una conversación". Expresado aquello, debemos resaltar que la lectura que queremos inculcar a la nueva generación está destinada a liberarlos del acuciante mundo en que vivimos y sumirlos en un mundo imaginario para no buscar en la lectura tan solo ideas o hechos, sino un desfile continuo de palabras que enriquezcan su mundo y su alma. Por último, Maurouis (1939) establece reglas sobre la lectura. La primera, es que vale más conocer perfectamente a algunos escritores $\mathrm{y}$ algunos temas, que conocer superficialmente un gran número de autores. La segunda, dar un lugar de preferencia a los grandes textos. Es tan necesario como natural, interesarse por los escritores de su tiempo, para no sumergirnos por la ola de pequeños libros. La tercera, aprender a conocer a nuestros autores. En literatura como en amor nos sorprendemos de las elecciones de los demás. Seamos fieles a lo que nos conviene. 
Y cuarta, poner alrededor de nuestras lecturas, siempre que sea posible, la atmósfera de recogimiento y de respeto que rodea un hermoso concierto, una noble ceremonia.

La carencia de conocimientos que impera en nuestros países latinoamericanos, tal como Ernesto Sábato describe en su obra "Antes del fin" (1999), ha permitido que grandes masas hayan sido empujadas hacia el vicio, $y$ hace en cuanto al asunto el uso de una frase que dice "un pueblo muere de hambre en campos no labrados", entendiendo que aquello discurre en la falta de cultura.

La enseñanza y con ello la lectura es una defensa más fuerte que la valla. En los objetos salvados del naufragio sigue -Piglia- en el "Ultimo lector" (2005), que se encarna la sociedad y termina expresando que la naturaleza y la experiencia de las cosas lo había llevado a percatarse que carecen de valor, a menos que podamos utilizarlas como la educación.

En este sentido, sigue el autor expresando que uno de los primeros instrumentos de la lectura, la Biblia, ha sido tan útil como el cuchillo, la pólvora y el tabaco. Y expresa Pligia (2005) una frase hermosa señalando que aquella es una prueba de que la Providencia existe.: "¿Cómo había rescatado si no los libros en el barco hundido?

También resulta necesario recordar lo que JeanFrancois Revel (1988) expresa en su importante obra "El conocimiento inútil" con una prosa brillante y una documentación implacable, "Hay que disimular a toda costa el hecho de que numerosos niños procedentes de ambientes modestos tienen más éxitos en sus estudios y en sus carreras que muchos niños procedentes de medios acomodados". Para lograrlo señala el autor que se ha ido pasando de la teoría a la práctica, hasta proponer reformas de la enseñanza expresamente concebidas para impedir a los niños más dotados y más trabajadores progresar más de prisa que los otros $\mathrm{y}$, termina expresando "Como todo buen alumno es sospechoso de serlo porque pertenece a las clases privilegiadas, y el buen alumno que no pertenece a ellas es culpable de desmentir la teoría, la justicia exige que todos los alumnos se vuelvan malos, a fin de que todos puedan volver a empezar juntos y con buen pie hacia un porvenir igualitario y radiante".

\section{LA NACIÓN - LA NACIÓN ECUATORIANA}

Hablar de identidad nacional lleva a tocar el tema de la nación. Federico Chabob, citado por Ruggiero Romano (Romano, 1992) dice que la idea de nación es para el hombre moderno algo espiritual, es alma, espíritu y después viene lo físico. Anderson (1996) indica que la educación es un elemento fundamental para la construcción de las naciones del siglo XX. Renan (1882) nos dice que la nación la conforman individuos que tienen muchas cosas en común y otras que han olvidado; nos dice, asimismo, que pueden existir comunidades sin patria que están unidas por la religión como era el caso de los israelitas. Así también, establece que la raza no determina a la nación, pueden existir algunas razas dentro de la misma nación. Es así, como en el Ecuador podemos encontrar catorce nacionalidades indígenas, convirtiéndolo en un país de diversidades; y aunque todos los países son heterogéneos en diversos aspectos, las diversidades en el Ecuador son más marcadas y se dan en muchas dimensiones, es un país complejo que cuenta con una variada situación geográfica, étnica, religiosa y social (Ayala, 2002). Es así como en la Constitución del Ecuador se apela a la sabiduría de todas las culturas que nos enriquecen como sociedad. El Ecuador es un Estado Constitucional de derechos y justicia, social, democrático, soberano, independiente, unitario, intercultural, plurinacional y laico (Constitución de la República del Ecuador, 2013). ${ }^{1}$ En la Nación Ecuatoriana coexisten culturas indígenas, mestizas y negras, así como, también generaciones de migrantes, lo cual ha originado fuertes identidades regionales (Ayala, 2002).

Pagnotta (2008) acota que "para que exista nación es necesario que sea contada". Assman

1 Constitución de la República del Ecuador, actualizada a marzo del 2013. 
(1997) señala que todas las comunidades políticas deben elaborar una estructura conectiva compartida que haga posible que los individuos se piensen como un nosotros; esta estructura está constituida por reglas, valores comunes y por el recuerdo de un pasado compartido. Vásquez (2003) afirma que la nación es un concepto que sintetiza la visión de una época y mediante un proceso de elaboración discursiva la universaliza, en tanto, es aceptada por la mayoría de los ciudadanos. Y es que según, Vásquez, las naciones surgen en un momento particular histórico, no tienen un carácter inmemorial aunque para su constitución moderna recurra a elementos tradicionales.

Anderson (2005) define a la nación como una comunidad política imaginada como inherentemente limitada y soberana. Explica que es imaginada porque sus miembros aunque no se conocen entre sí, viven una implícita comunión, es limitada porque nadie ha pensado darle la dimensión de humanidad, es soberana porque el concepto nació en el contexto de la Ilustración, cuando la Revolución Francesa estaba destruyendo la idea del reino dinástico jerárquico de origen divino; y es comunidad porque la idea de nación se concibe como un compañerismo profundo y horizontal, que sobrepasa las desigualdades y explotación que se le dan en la realidad.

\section{LA IDENTIDAD NACIONAL}

La identidad nacional se refiere a un proceso de auto-identificación, de cobrar conciencia de uno mismo desde la raza, desde la cultura, es un proceso intelectual de reconocimiento de unos valores generales, por los cuales la persona se identifica como uno más incluido en un grupo definido por dichos valores (Altarejos, 2007). Es la identificación de nosotros y una toma de conciencia de ser distintos a los demás pero iguales a sus co-societarios frente a los otros grupos (Ibañez, 2013). Este autor la define, asimismo, como una vinculación ideológica y afectiva al grupo humano de una colectividad unida por lazos de homogeneidad cultural, la conciencia defensiva de la unidad de costumbres, instituciones, lengua, religión y de afinidades electivas y congénitas y los proyectos de vida común.
La identidad nacional puede ser definida como el sentimiento subjetivo del individuo por pertenecer a una nación concreta, a una comunidad conformada por distintos elementos que la hacen única y diferente, tales como lengua, religión, cultura, etnias, y es en base a estos elementos que se asienta el sentimiento de pertenencia a una comunidad nacional (Talavera Fernández, 1999).

Según Guibernau (2009) la identidad nacional la estructuran las siguientes dimensiones; psicológica, cultural, histórica, territorial y política, donde las élites cumplen una función importante en la construcción de la misma a través de estrategias implementadas por el Estado-Nación. Este autor explica cada una de estas dimensiones. La dimensión psicológica podría ser definida como el sentimiento compartido por un grupo de personas que supera la razón, y cuando esta idea de nación es enaltecida, la autoestima es elevada, dándole mayor importancia a sus vidas. La dimensión cultural está caracterizada por el factor emocional, que involucra los valores, creencias, costumbres, convencionalismos, hábitos, lengua y las prácticas sociales que pasan de generación en generación. En cuanto a la historia, su uso selectivo contribuye a la memoria colectiva, lo cual facilita que se construya la imagen de una nación que forma el carácter nacional, esta ciencia social une al pueblo con sus ancestros y así se cree que se forma parte de una gran familia. El territorio es aquel espacio en el que la gente piensa que toman forma sus tradiciones, la historia, y la cultura de la nación, el mismo que ha sido compartido con sus ancestros y se hereda a las nuevas generaciones, es así como la defensa del medio ambiente tiene actualmente un lugar predominante en el concepto de identidad nacional. En cuanto a la dimensión política, ésta puede ser definida como la propiedad que comparten los ciudadanos de un Estado-nación e incorpora las propiedades de racionalidad jurídica, el orden y el poder.

Para Célica y Alvarez (2008) la identidad nacional es un sentimiento colectivo basado en la creencia de pertenecer a una comunidad imaginada como nación; los sujetos que la integran y que se integran a ella, comparten un vínculo emocional, que no es racional ni tampoco irra- 
cional, pero que los hace pensar que tienen ancestros comunes. Añaden estos autores que los atributos reales o inventados que comparten los miembros de la nación juegan un papel importante en el sentimiento colectivo de pertenencia y continuidad, aunque estos atributos podrían ser estereotipos creados con la selección de rasgos distintivos de una identidad nacional fluida y constante, cuyo origen está en la modernidad.

\section{LA IDENTIDAD NACIONAL ECUATORIANA}

Robalino, citado por Benjamín Carrión, (1959) dice que el Ex Presidente Gabriel García Moreno todo lo quería importar del extranjero, era ecuatoriano por azar de nacimiento. Nunca tuvo fe en nada ecuatoriano. Es el creador del sentido de inferioridad nacional, que es nuestro mal mayor a través de la historia. Viene desde allí, entonces, nuestra crisis de identidad nacional.

A decir del escritor ecuatoriano Donoso (2004) la identidad ecuatoriana es "esquizofrénica" debido a sus contradicciones que pueden llevar a la locura total y a un país a "su disolución, a desmoronarse o a caerse en pedazos". Por su parte Adoum (2000) nos dice que ecuatoriano es evidentemente aquél que nació o se naturalizó aquí pero eso querría decir que todos los ecuatorianos tienen las mismas facciones, y es que como él dice, identidad puede confundirse con las señas particulares que podemos tener en común, y de ser así, compartiríamos estas señas con otros pueblos de América Latina.

Adoum (2000) indica que identidad es "el hecho de ser una persona o cosa la misma que se supone o busca" y eso nos plantea el desafío de saber qué buscamos o qué suponemos ser". Donoso (2004), en cambio, sostiene que el regionalismo que ha regido en el país por muchísimos años dificulta el saber qué es lo que buscamos como país porque tenemos objetivos e intereses diferentes, no hay unidad sino enfrentamiento entre regiones. Por eso, Belisario Quevedo en sus "Notas sobre el carácter del pueblo ecuatoriano" (Donoso, 2004) dice que "hay dos tipos del pueblo ecuatoriano: el costeño, que habita en clima ardiente y por cuyas venas corre mucha sangre negra y el serrano del clima benigno que tiene cuatro quintos de sangre india, si acaso no es indio puro. La sierra es romántica, la costa positivista”.

Se señala, a criterio de Adoum (2000) que la identidad colectiva no es algo que no pueda cambiarse, que venga de siglos anteriores como algo impuesto, se va formando con los rasgos, aunque incompletos y no siempre nos agrada. El mismo autor aclara que las culturas puras no existen, y las que existieron ya desaparecieron hace mucho tiempo. Asimismo señala que la identidad es la raíz más honda y profunda que los pueblos han sembrado en la historia y sus elementos (etnia, lengua, religión, ética, conciencia de nación...) pueden haber estado enterrados por muchísimos años y de repente surgir orgullosamente o de forma violenta. "La búsqueda del Ecuador por su identidad comenzó no hace mucho tiempo y talvez no termine jamás, muchos han hablado de rescatarlo como si alguien nos la hubiese arrebatado" (Adoum, 2000).

De acuerdo a Moya (1997) "tanto en el Ecuador, como en el resto de América Latina, la identidad nacional es un proyecto que no cuaja hasta el presente y que cada vez parece ser menos viable, en la medida en que trata de configurar una identidad homogeneizadora y excluyente, mimetizada y deducida, de espaldas al problema étnico y a la diversidad cultural". Continúa esta autora diciendo que el hecho colonial podría ser una causa, pero no es la única porque ésta podría ser el mestizaje debido a que la población mestiza prefirió unirse a la cultura dominante y negó y olvidó su origen. Los pueblos indígenas han decidido luchar por sus derechos y exigir una reinterpretación de la historia nacional y de sus historias particulares. La existencia de las nacionalidades indígenas y del pueblo multiétnico de los quichuas reafirma el carácter pluriétnico del Ecuador y establece la necesidad de construir una identidad nacional basada en lo diverso y en la revalorización de las raíces históricas y culturales ancestrales. Es así que la actual Constitución del Ecuador establece que "el país es un Estado constitucional de derechos y justicia, social, democrático, soberano, independiente, unitario, intercultural, plurinacional, y laico". Asimismo de acuerdo a la Constitución, el Estado respetará y estimula- 
rá la conservación y uso de los idiomas ancestrales de los pueblos indígenas.

Vásquez (2003) señala que la identidad nacional ecuatoriana se refiere a una forma de sentirse ecuatorianos, dependiendo del grupo humano que lo hace; para los jóvenes, ecuatoriano hace referencia a una serie de elementos identificadores y compartidos por todos los ecuatorianos pero que ellos lo viven y lo sienten de manera diferente.

\section{LA LITERATURA INFANTIL Y SU ROL EN IBEROAMÉRICA}

Al hablar de literatura infantil y su rol en la formación de identidades nacionales es importante hacer un recorrido por sus comienzos y sus transformaciones. Este género literario, en tanto que entidad cultural definida es, en Iberoamérica, un producto del siglo XX (Rosell, 2013). Es así, que su adelanto o retraso depende del desarrollo económico, social, educativo y cultural de cada país. En el siglo XIX solamente hubo intentos o tanteos con producciones tales como: silabarios, textos para la formación de jóvenes élites, las primeras fábulas en prosa y verso, compilaciones de cuentos populares, etc. El folklore, dice el mencionado Rosell, ha sido una de las representaciones más importantes de la literatura infantil en Iberoamérica y, prosigue, diciendo que uno de los problemas más evidentes del libro infantil en América Latina es la pobreza y la injusta distribución de la riqueza, la escolarización insuficiente y lo precario de las librerías y editoriales que no son capaces de crear obras literarias apropiadas para los niños y que los conecten con su realidad. Lamentablemente hay poco respeto por la identidad nacional y las obras que se producen no siempre procuran inculcar este sentimiento en los niños y jóvenes.

"La literatura infantil en Latinoamérica debe esforzarse por formar una epistemología propia, por buscar en sus raíces los cimientos de este género literario, debe existir una concepción auténtica porque aún estamos ligados a lo extranjero". (Sánchez, 2002).

Sánchez (2002) continúa diciendo que no existe una relación más profunda que la que hay entre la literatura infantil y la identidad cultural, pues la literatura actúa en la formación del mundo que tiene o tendrá el niño, lo liga con su realidad y lo proyecta en su historia. Es decir, que la literatura infantil debe ser el medio que nos ayude a descubrir de dónde venimos, quiénes somos y hacia donde nos dirigimos. $\mathrm{Y}$ es que la literatura tiene un instrumento sumamente poderoso que es el lenguaje y los latinoamericanos debemos utilizar un lenguaje común a nuestras experiencias.

La relación entre identidad y literatura infantil ha sido analizada por autores latinoamericanos; Torres (1997) para analizar este tema toma como ejemplos a Martí de Cuba con la revista "La edad de Oro" (1972), y a Hostos de Argentina con su obra "En barco de papel" (1988) y dice que estas obras "combinan los temas de identidad nacional y emancipación con la presentación de problemas existenciales que obligan al lector a buscar soluciones".

Sánchez (2002) al analizar la identidad en la literatura infantil argentina define a la identidad como "la presencia constante de determinadas características particulares que permiten que ciertos objetos sean reconocidos como tales, en este caso, una obra literaria". Señala, también, que para identificar la identidad de una nación o de un continente, es necesario, no solamente, puntualizar sus diferencias en relación a otras geografías o idiosincrasias, sino también referirse a sus aspectos universales. Por eso ella también cuestiona la influencia de la globalización en la literatura porque pone en peligro la supervivencia de la literatura latinoamericana, es decir, que la industria cultural podría acabar con la identidad de nuestros pueblos.

Berríos (2010), creador de libros para niños en Honduras, puntualiza que es en la década de los 80 cuando la literatura infantil hondureña produce "obras de alta calidad artística apegadas a su realidad y rechaza a la sub-literatura extranjera que niega nuestros valores culturales y aliena el alma y la vida del niño". Asegura él que la literatura infantil se va abriendo paso poco a poco, llegando a más corazones infantiles y de adultos día a día. 
Rosell (2010) expresa que existen importantes representantes de la literatura que han hecho un gran aporte a la formación y consolidación de la identidad nacional tales como José Hernández (Argentina), Jorge Isaacs (Colombia), José María Heredia (Cuba), Neruda (Chile), Rómulo Gallegos (Venezuela), Santos Chocano (Perú), entre otros.

Díaz (2011) señala que hay una sobreproducción de literatura infantil en Latinoamérica y que esta literatura es muy diversa, recoge tradiciones indígenas, raíces afro-descendientes y la conquista española, y también la diferencia geográfica entre zonas rurales, urbanas y costeras. Además, dice, que en esta literatura predominan "la riqueza del mestizaje, la denuncia social pero también hay una abundancia poética". Asimismo, este autor dice que América Latina es sinónimo de mestizaje, y esto posibilita que en nuestra literatura infantil se encuentren diversas culturas, como la indígena, la africana, la española y una literatura vernácula que está en permanente búsqueda.

Botero (2004) nos dice que "cada día, con más fuerza, en el Ecuador se perfilan autores con temáticas y tratamientos propios, aquí hay voces maduras que comienzan a ser reconocibles y apetecidas para los pequeños". Entre estas voces maduras tenemos a los escritores ecuatorianas Edna Iturralde con libros como "María Manglar", María Fernanda Heredia con su obra "Amigo se escribe con H", Leonor Bravo con su "Viaje por el país del sol" y Edgar Allan García con su obra "El país de los juguetes".

Cabera (2002) se pregunta si la literatura infantil latinoamericana está solamente formada por piezas nacionales inconexas y diferentes que no permiten una concepción global de la misma, o si sería justo y oportuno reclamar o hablar de una literatura infantil latinoamericana con características definitorias de un único fenómeno. Asimismo, señala que en la literatura latinoamericana para adultos sí ha habido una mejor distribución, lamentablemente, la literatura infantil no ha sido distribuida de la misma manera. Haciendo un análisis de la trayectoria de la literatura infantil latinoamericana a través de los años, el autor antes mencionado, expone que durante la primera mitad del siglo XX la literatura infantil en Latinoamérica fue escasa y poco significativa, a excepción de obras individuales de autores reconocidos, las obras infantiles fueron pobres y muy rara vez atravesaban las fronteras nacionales; es recién en la década de los 70 que gracias a cambios políticos, económicos y tecnológicos, los países experimentan una gran producción creativa que origina un fuerte movimiento literario en el campo de las letras para niños y jóvenes.

\section{LAS CARACTERÍSTICAS DE LA LITERATURA INFANTIL ECUATORIANA}

En el libro "Rehaciendo la nación" (Radcliffe, S. y Westwood,S., 1999) se hace un estudio sobre la realidad del Ecuador y se establece que el país no traza su historia hasta más allá de la pre-conquista y no hasta el Imperio Incaico pero esto ha cambiado y actualmente a los niños y jóvenes ecuatorianos se les da una visión completa de los antecedentes del Ecuador, de su nacimiento y su realidad. Y la literatura infantil ecuatoriana que, según la escritora ecuatoriana Leonor Bravo (2013) ha despuntado en los últimos diez años, está convirtiéndose en un recurso para ayudar a los jóvenes ciudadanos a conocer e identificarse con su país. La literatura infantil ecuatoriana, según esta escritora, es una literatura mestiza que responde al carácter intercultural del país, ya sea al recoger sus mitos y tradición oral, al abordar temas ligados a la historia y al devenir de las diferentes culturas que conforman nuestra nación, o expresándose a través de modismos del habla coloquial ligados al quichua y otras lenguas vernáculas. Esta literatura está caracterizada por ambientes como la selva y páramos, el mar y los volcanes. Asimismo, esta literatura responde a las nuevas realidades del país, niñas y niños protagonistas de su vida que conocen sus derechos y necesitan libros que hablen su lenguaje, interpreten sus sueños, su visión del mundo y sus necesidades. El género más utilizado es la narrativa, específicamente el cuento corto. Se está produciendo en el país una gran cantidad de producción de novelas infantiles y juveniles. En cuanto a la poesía, no se publica tanto porque no tiene la misma acogida que los libros de narrativa que tienen mejor recepción. La literatura infantil en 
el Ecuador no ha sido escrita en ninguna de las otras lenguas que se hablan en el país a pesar de la larga tradición de recolección y difusión de leyendas y literatura oral de las distintas culturas del país, pero esto es tratado de forma didáctica o antropológica, sin llegar al nivel literario.

Heredia (2007) indica que la literatura infantil ecuatoriana vive un gran momento, la calidad de las obras literarias no solamente se ratifica por los miles de lectores que disfrutan de historias escritas por ecuatorianos, sino porque estas obras están traspasando las fronteras. Acota esta autora que la frase "cada vez se lee menos" no aplica a la literatura infantil.

García (2007) señala que la literatura infantil se ha convertido en un fenómeno que reúne cada vez a más niños y adultos atraídos por mundos, personajes y ambientes que embrujan, estremecen y enseñan. Sin embargo, este autor, expresa que es preocupante que no exista una política editorial para internacionalizar la literatura infantil ecuatoriana.

Iturralde (2007) comenta sobre su trayectoria como escritora de obras infantiles y dice que éstas han acompañado a aproximadamente dos generaciones de niños ecuatorianos, traspasando las fronteras hasta España, Perú, Bolivia, México, Colombia y Estados Unidos; y aunque, no es historiadora sus obras permiten que los niños y jóvenes se transporten al pasado, aunque tampoco es antropóloga, sus escritos tienen un componente étnico y humano, no es maga pero crea mundos mágicos.

\section{LOS LIBROS INFANTILES ECUATORIANOS Y LA DIVERSIDAD CULTURAL Y RACIAL}

Es necesario resaltar que los libros infantiles ecuatorianos están procurando difundir la diversidad racial y cultural de nuestro país. Así tenemos el libro denominado “...y su corazón escapó para convertirse en pájaro" (Iturralde, 2001). Este libro consta de relatos sobre el pueblo negro ecuatoriano que datan desde el siglo XVI hasta nuestros días. Se estima que entre el cuatro y el nueve por ciento de la población ecuatoriana son afro-ecuatorianos. El pueblo negro ecuatoriano ha vivido mayoritariamente en el Valle del Chota y la Cuenca del río Mira, en la provincia de Imbabura, y en la provincia de Esmeraldas; también, se encuentran en las provincias del Guayas, El Oro, Pichincha y Sucumbíos, y en menor proporción en las provincias restantes. Dentro del libro infantil mencionado se encuentra un relato que es digno de mencionarse, su título es "El viaje" y cuenta cómo entre 1450 y 1850 , aproximadamente doce millones de africanos fueron raptados y vendidos como esclavos. Muchos fueron embarcados desde África a través del Atlántico en lo que ha sido llamado "El viaje amargo del dolor" y transportados hacia las colonias europeas de Norte, Centro y Sur América; este suceso en el cual los africanos fueron separados y dispersados es conocido como "Diáspora". De igual manera, se incluyen otros relatos en los cuales se narra la vida de los afro-ecuatorianos como esclavos en las haciendas de siglos pasados.

Y siguiendo con el papel de la literatura infantil ecuatoriana en la difusión de la diversidad cultural y racial, tenemos el libro "Verde fue mi selva" (Iturralde, 1998), en el cual se relatan diferentes historias que se desarrollan en la Amazonía y sus protagonistas son los achuar, shuar, huaorani, secoya, siona, quichua y cofán. El mencionado libro explica a través de relatos fantásticos y mágicos las costumbres de estos grupos étnicos.

En el libro "Viaje por el país del sol" (Bravo, 1995) los personajes protagónicos, Manuela y Mateo, a pedido de sus abuelos recorren todo el país y como recompensa recibirán un tesoro, que resulta ser el Ecuador. Este libro no sólo promociona al país sino que despierta en los niños la curiosidad y el interés por conocer su territorio, y es que no se puede amar lo que no se conoce.

\section{CONCLUSIONES}

En el presente articulo se han expuesto diversas concepciones en cuanto a la identidad nacional. De acuerdo a Altarejos (2007) la identidad nacional es un proceso de autoidentificación, de identificarnos con un grupo de personas con quienes compartimos ciertos valores. Es sentir, como dice 
Ibañez (2013), que nos vinculamos a un grupo humano por aspectos en común. Es asimismo, como dice Talabera (1999), el sentir que pertenecemos a una nación concreta, experimentar ese sentimiento de pertenencia a una comunidad nacional. Como dicen Célica y Alvarez (2008) se refiere a ese vínculo emocional que nos une a las personas que conforman una nación.

Hay países que tienen una debilitada identidad nacional y el Ecuador es uno de ellos. Como dice Donoso (2004), es una identidad esquizofrénica debido a sus contradicciones; además, no hay unidad sino enfrentamiento entre regiones. Adoum (2000) señala que la búsqueda del Ecuador por su identidad comenzó no hace mucho tiempo y talvez este proceso nunca termine. $Y$ es que como indica Moya (1997), tanto en el Ecuador como en el resto de América Latina, la identidad nacional es un proyecto que aún no termina de implantarse.
¿Por qué es necesario que los integrantes de una nación se identifiquen con ella? Porque solamente asi lucharán por sacarla adelante, por lograr la unión y formar una nación fuerte que no se debilita ante las adversidades. Este sentimiento debe ser inculcado en las nuevas generaciones desde edades tempranas, surge asi la necesidad de saber cómo hacerlo, y la Literatura Infantil se nos presenta como un buen recurso para que los niños y jóvenes se identifiquen con su nación porque de manera sencilla pero eficiente y a través de la magia y la fantasía transporta a los niños a sus raices para poder afianzarse en el presente y proyectarse en el futuro. Esta labor es ardua porque en el Ecuador aún falta por tomar a este género literario de manera más seria.

\section{REFERENCIAS}

Adoum, J. (2000). Ecuador: Señas particulares. Quito: Eskeletra Editorial.

Ayala, E. (2002). Ecuador: Patria de todos. La nación ecuatoriana, unidad en la diversidad. Quito. Universidad Andina Simón Bolívar. Sede Ecuador.

Altarejos, F. (2007). Retos educativos de la globalización. Navarra: Universidad de Navarra.

Arias, M. y Hadis, M. (2000). Borges Profesor. Buenos Aires: Emecé Editores.

Assman, J. (1997). La memoria culturale.Torino: Einaudi.

Berríos, R. (2010). La literatura infantil en Honduras. www.biblioteca.org.ar/ Recuperado el 10 de Julio del 2013.

Botero, M. (2004). Literatura infantil en Ecuador, con voz propia. www.eluniverso.com. Recuperado el 12 de julio del 2013 .

Bravo, L. Panorama actual de la literatura infantil ecuatoriana. www.prensajuvenil.org. Recuperado el 27 de julio del 2013.

Bravo, L. (1995). Viaje por el país del sol. Quito: Santillana S.A.

Cabera, L. Nuevo enfoque de estudio en la literatura infantil latinoamericana. letras-uruguay.espaciolatino.com/

Carrión, B. (1958). El santo del patíbulo. Quito: Casa de la Cultura Ecuatoriana.

Célica, E. y Alvarez, A. www.comunicación.ugto.mx/. Recuperada el 29 de julio del 2013.

Constitución de la República del Ecuador. Actualizada a marzo de 2013. 


\section{LA LITERATURA INFANTIL COMO FORMADORA DE IDENTIDADES NACIONALES, EN ECUADOR Y EN SUDAMÉRICA}

Diario El Universo. Primera sección, p. 2. 29 de julio del 2013.

Díaz, F. (2011). Literatura infantil latinoamericana, Fanuel Hanán Díaz. www.dondevivenloslibros.com/2011. Recuperado el 11 de julio del 2013.

Donoso, M. (2004). Ecuador: identidad o esquizofrenia. Quito: Eskeletra Editorial.

García, E. Autores hablan sobre la relación de los libros con los niños. www.eluniverso.com/2007

Guibernau, M. (2009) La identidad de las naciones. Barcelona: Ariel.

Heredia, M. Autores hablan sobre la relación de los libros con los niños. www.eluniverso.com/2007

Ibañez, A. Identidad nacional. www.sisman.utm.edu.ec. Recuperado el 27 de julio del 2013.

Iturralde, E. (2008). El cóndor, el héroe y una historia de independencia. Quito: Grupo Santillana.

Iturralde, E. (2001). ...y su corazón escapó para convertirse en pájaro. Quito: Santillana.

Iturralde, E. (1998). Verde fue mi selva. Quito: Santillana.

Iturralde, E. Autores hablan sobre la relación de los libros con los niños. www.eluniverso.com/2007

Maurois, A. (1939). Un arte de vivir. Santiago de Chile: Editorial Letras.

Moya, L. (1997). Pluriculturalidad e identidad nacional en el Ecuador. www.sek.edu/. Recuperado el 28 de julio del 2013.

Pagnotta, C. (2008). La identidad nacional ecuatoriana entre límites externos e internos. www.alhim.reves.org/. Recuperado el 12 de julio del 2013.

Piglia, R. (2005). El último lector. Barcelona: Editorial Anagrama.

Radcliffe, S. y Westwood, S. (1999). Rehaciendo la nación. Lugar, identidad y política en América Latina. Quito: AbyaYala.

Renan, E. ¿Qué es una nación? Conferencia dictada en la Sorbona, París, el 11 de marzo de 1882.

Revel, J. (1988). El conocimiento inútil. Barcelona: Editorial Planeta.

Robalino, L. (1974). Orígenes del Ecuador de hoy. Quito: Editorial J.M. Cajica Jr.

Romano, R. (1992). Consideraciones: Siete estudios de historia. Lima: Fomciencias-Instituto Italiano de Cultura.

Rosell, J. Otro Lunes. Revista Hispanoamericana de Cultura. www.otrolunes.com

Sábato, E. (1998). Antes del fin. Buenos Aires: Compañía Editora Espasa Calpe.

Sánchez, C. (2002). La identidad en la literatura infantil argentina. Ser o no ser en el mundo. www.imaginaria.com.ar. Recuperado el 29 de julio del 2013. 
Talavera, P. (1999). El valor de la identidad. Cuadernos electrónicos de filosofía del derecho, No. 2 . Recuperado el 27 de julio del 2013.

Vázquez, L. (2003). La nación ecuatoriana desde los jóvenes. Percepción de los jóvenes y las jóvenes sobre la nación y la identidad nacional. repositorio.uasb.edu.ec/. Recuperado el 29 de julio del 2013. 
